\title{
ANÁLISE ESTRATIGRÁFICA DA BACIA DO ARARIPE, NORDESTE DO BRASIL
}

\author{
MARIO L. ASSINE*
}

\begin{abstract}
STRATIGRAHUC ANALYSIS OF ARARIPE BASIN, NORTHEASTERN BRAZIL. The Araripe Basin comprises four main stratigraphic sequences separated by unconformities: 1. a Paleozoic sequence composed of the Cariri Formation; 2. a Juro-Neocomian sequence composed of the Brejo Santo Formation, Missão Velha Formation (redefined) and Abaiara Formation; 3. an Aptian-Albian sequence composed of the Barbalna Formation and Santana Formation; and 4. an Albian-Cenomanian sequence composed of the Exu Formation. The JuroNeocomian sequence is characterized by horsts and grabens displayed in two sub-basins: Cariri and Serrolândia subbasins. The Aptian-Cenomanian is characterized by sub-horizontal bedding and localized brittle deformation. The events of sedimentation, erosion, and deformation proposed for the sequences above, integrate the Phanerozoic evolution in Northeastern Brazil. The Paleozoic deposits which have, in attempt, been classified as Upper Ordovician/ Lower Silurian, have also been interpreted as an extension of the cratonic Parnaiba Basin. The Juro-Neoconian sequence is $\dot{u}$ » sedimentary response to the mechanical subsidence brought about by the Gondwana rifting processes. The Barbalha and Santana formations comprise a transgressive-regressive cycle characterized by short-lived sea ingression which has deposited an exuberant fossiliferous carbonate concretions level and extensive gypsum beds. The presence of alluvial deposits of Exu Formation, deposited contemporaneously to a global eustatic sea level rising, suggests an epeirogenic uplift early in the Albian-Cenomanian time.
\end{abstract}

Keywords: Stratigraphy, Araripe Basin, Northeastern Brazil.

RESUMO A Bacia do Araripe é constituída por quatro seqüências estratigráficas, histórica e geneticamente distintas, limitadas por discordâncias. As quatro seqüências correspondem a quatro embaciamentos distintos, dos quais somente uma fração da cobertura original está preservada, não havendo porções marginais e depocentros definidos. Os eventos de sedimentação, erosão e deformação não constituem fatos isolados, integrando-se no contexto evolutivo do fanerozóico nordestino. A seqüência paleozóica, constituída unicamente pela Formação Cariri e tentativamente posicionada no Ordoviciano Superior/Siluriano Inferior, integrava um extenso trato com mergulho deposicional para noroeste, testemunhando uma maior extensão oriental da Bacia do Pamaíba no Paleozóico inferior. A seqüência juroneocomiana, composta pelas formações Brejo Santo, Missão Veiha e Abaiara, foi a resposta sedimentar à subsidểncia mecânica decorrente dos processos de rifteamento do Gonduana. Seus sedimentos apresentam-se espacialmente em horstes e grábens, dispostos em duas sub-bacias: Cariri e Serrolândia. A seqüência aptiano-albiana, constituída pelas Formações Barbalha e Santana, compreende um ciclo transgress!vo-regressivo com ingressão marinha de curta duração, à qual se associa exuberante nível de concreções carbonáticas fossilíferas e extensas jazidas de gipsita. Ainda em condições eustáticas positivas a nível global, foram depositados os sedimentos aluviais da seqüência albiano-cenomaniana (Formação Exu), indicando uma reativação tectônica com soerguimento epirogênico da região já no Albiano Médio/Superior.

Palavras-chaves: Estratigrafia, Bacia do Araripe, Nordeste do Brasil.

INTRODUÇÃO A Bacia do Araripe é a mais extensa das bacias interiores do Nordeste do Brasil (Fig. 1). Sua área de ocorrência não se limita à Chapada do Araripe, estendendo-se também pelo Vale do Cariri, num total de aproximadamente $9.000 \mathrm{~km}^{2}$.

O trabalho pioneiro sobre sua geologia é o de Small (1913), que subdividiu o registro sedimentar em quatro unidades (conglomerado basal, arenito inferior, calcário Santana e arenito superior). Estudos sistemáticos foram realizados somente a partir da década de 60, um período de profícuos trabalhos, como os desenvolvidos por professores e alunos da Universidade Federal de Pernambuco, de que resultaram publicações como as de Beurlen (1962, 1963). Este autor redefiniu as unidades estabelecidas por Small, denominando-as de formações Cariri, Missão Velha, Santana e Exu, para as quais estimou uma espessura sedimentar total de cerca de $850 \mathrm{~m}$.

Dentre as unidades litoestratigráficas da bacia, a Formação Santana é estratigraficamente a mais complexa e também a mais estudada, não só pelas extensas jazidas de gipsita, mas principalmente por se constituir no principal jazigo brasileiro, famoso em todo mundo sobretudo pela rica paleoicniofauna preservada em concreções carbonáticas.

Rand \& Manso (1984), com base em dados gravimétricos, calcularam espessuras sedimentares totais da ordem de $2.400 \mathrm{~m}$, despertando interesse quanto às potencialidades petrolíferas da bacia, o que levou seis empresas nacionais a assinarem contratos com a PETROBRÁS, para exploração de petróleo com cláusula de risco. Dentre os trabalhos desenvolvidos, merecem destaque o mapeamento geológico da bacia na escala $1: 100.000$, o levantamento de $250 \mathrm{~km}$ de linhas sísmicas de reflexão e a perfuração de um poço profundo (2-AP-1-CE, Araripe Estratigráfico $\mathrm{n}^{\circ} 1$ ), que permitiram estimar uma espessura sedimentar da ordem de $1700 \mathrm{~m}$.

$\mathrm{O}$ acervo destas novas informações e de novos dados obtidos em campanhas de campo subseqüentes propiciaram o desenvolvimento da dissertação de mestrado "Sedimentação e Tectônica da Bacia do Araripe, Nordeste do Brasil", apresentada pelo autor em 1990 à UNESP - Campus de Rio Claro. Este trabalho é uma síntese dos resultados alcançados, enriquecida com as proposições apresentadas por Ponte \& Appi (1990).

SEQUÊNCIAS ESTRATIGRÁFICAS A análise estratigráfica realizada, centrada na identificação dos eventos geológicos maiores, reconhecíveis ao longo de toda a bacia, evidenciou que os sedimentos preservados na Bacia do Araripe não testemunham embaciamentos completos, com porções marginais e depocentros definidos. Constituem o registro fragmentário de quatro bacias histórica e geneticamente distintas, separadas no tempo e parcialmente superpostas no espaço, materializadas por quatro seqüências estratigráficas limitadas 


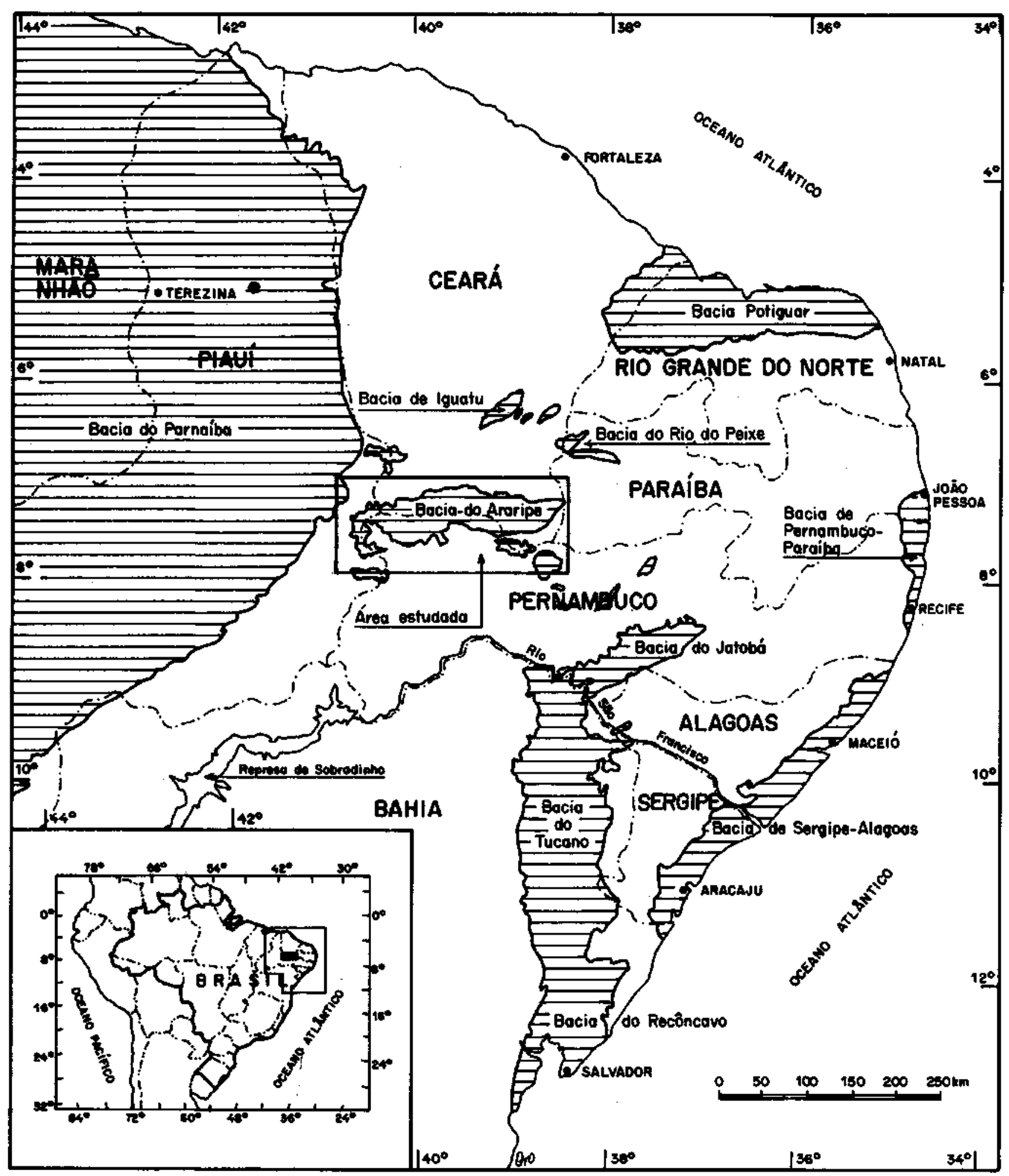

Figura 1 - Mapa da região Nordeste do Brasil, mostrando a localização da Bacia do Araripe Figure l - Map of Northeastern Brazil showing the location of the Araripe Basin

inteiramente por discordancies, hierarquicamente correspondentes aos sintemas de Chang (1975).

São discutidas, a seguir, cada uma das quatro seqüências identificadas, buscando-se caracterizar a arquitetura deposicional da bacia. Ao mesmo tempo, como a nomenclatura estratigráfica é necessária à comunicação e cartografia geológicas, especial- mente numa bacia que ainda carece de mapeamentos geológicos básicos, procurou-se discutir conjuntamente sua litoestratigrafia. Também, porque as diferentes colunas estratigráficas propostas para a bacia (Fig. 2) evidenciam a não-concordância dos diversos autores no que concerne à divisão, nomenclatura, idade e relações de contato entre as diversas unidades estratigráficas. 


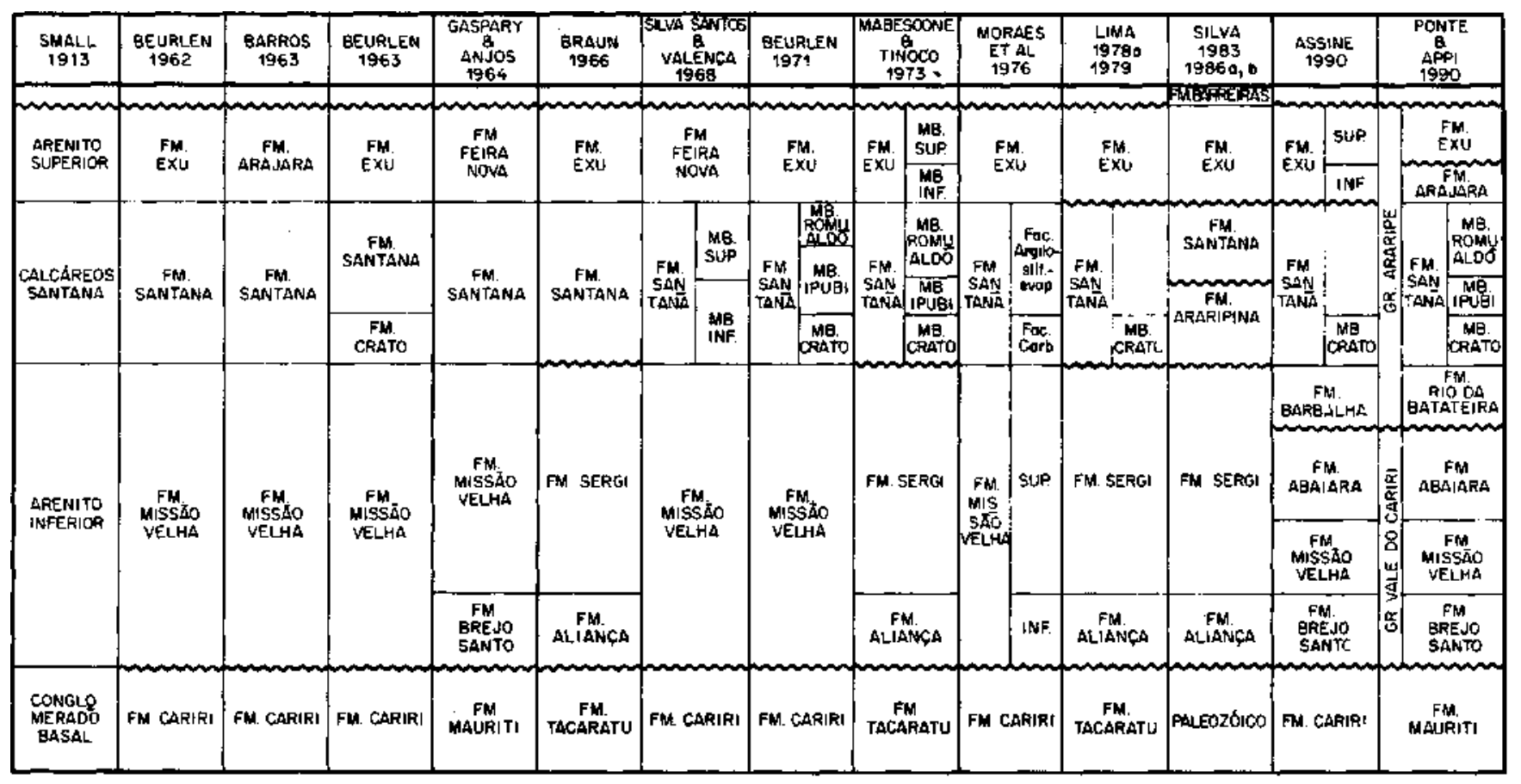

Figura 2 - Quadro comparativo das colunas litoestratigráficas propostas para a Bacia do Araripe (modificado de Lima 1979) Figure 2 - Comparative table of different lithostratigraphic columns proposed for the Araripe Basin (modified after Lima 1979)

As relações espaço-temporais entre as unidades identificadas estão sintetizadas na coluna estratigráfica proposta para a bacia (Fig. 3).

Seqüência Paleozóica Composta unicamente pela Formação Cariri, aflora na porção leste da bacia definindo os contornos do Vale do Cariri (Fig. 4). Não se restringe, porém, a ele, ocorrendo para além de seus limites em áreas isoladas de variadas dimensões. Sua espessura é reduzida, talvez nunca ultrapassando uma centena de metros. Na parte oeste da bacia não aflora, ocorrendo apenas em subsuperfície, como na subbacia de Serrolândia onde foi perfurado o 2-AP-1-CE (Fig. 5), que atravessou $46 \mathrm{~m}$ de sedimentos desta seqüência.

FORMAÇÃO CARIRI Constitui-se quase que exclusivamente de arenitos, onde descontínuos níveis decimétricos de siltitos brancos com tonalidades arroxeadas completam o quadro de uma unidade litologicamente monótona. Na parte inferior predominam arenitos feldspáticos, freqüentemente verdadeiros arcósios. São brancos com tons róseos, têm granulometria média a muito grossa, muitas vezes conglomerática, com grãos angulares a subangulares. Níveis de conglomerados ocorrem, sendo mais comuns na base onde incluem fragmentos líticos do embasamento e feldspatos bem preservados. Em direção ao topo, os arenitos feldspáticos gradam para arenitos quartzosos branco-acinzentados de granulometria média a grossa, com seixos de quartzo dispersos ou acompanhando os planos de estratifícação, quando por vezes formam níveis delgados de conglomerados quartzosos. Característica diagnostica destes arenitos é a ocorrência disseminada de minerais esverdeados, identificados por Feitosa (1987) como palygorskita (argilomineral flbroso).

As estratificações são geralmente cruzadas de médio porte, tabulares planares e secundariamente acanaladas, em sets com espessuras decimétricas a métricas. São interpretadas como originadas em sistemas fluviais entrelaçados (braided), com escassez acentuada da fração pelítica de planície de inundação.

Como os sedimentos são essencialmente siliciclásticos, até o momento sem registro de fósseis, a tentativa de posicionamento cronoestratigráfico tem necessariamente que basear-se em comparações com as bacias vizinhas. Admitindo-se a correla- ção litoestratigráfica de Caputo \& Crowell (1985), estão preservados na Bacia do Araripe sedimentos correlates à Formação Ipu, base do Grupo Serra Grande da Bacia do Parnaíba. Tal formação ocorre estratigraficamente abaixo da Formação Tianguá daquela bacia, considerada de idade eo-siluriana por $\mathrm{Ca}-$ rozzi et al. (1975) e por Caputo \& Uma (1984).

Caputo \& Lima (1984) relataram a ocorrência de diamictitos dentro da Formação Ipu na área da Serra Vermelha (Piauí), e no contato com a Formação Tianguá no poço 2-CI-1 MA (Cocalinho Estratigráfico $\mathrm{n}^{8} 1$ ). Neste contexto, a amarração à glaciação neo-ordoviciana/eo-siluriana, um evento reconhecível em todo o Gonduana e fartamente registrada na África e América do Sul (Berry \& Boucot 1972, Hambrey \& Harland 1981), permite um posicionamento cronoestratigráfico tentativo no Ordoviciano Superior/Siluriano Inferior. Idade siluriana inferior é também admitida por Ghignone (1979) para os sedimentos Serra Grande/Tacaratu, aflorantes no Estado da Bahia. Os sedimentos da Bacia do Araripe teriam sido depositados antes mesmo do ciclo glacial, possivelmente em condições climáticas quentes e secas, como sugere a presença de palygorskita.

Tais correlações e suposições ainda carecem de dados mais conclusivos, de forma que litoestratigraficamente é recomendável a utilização de uma denominação oriunda da geografia local, que não precise ser alterada quando diferentes correlações são aventadas. Dentre as várias denominações que têm sido utilizadas, é sugerida a manutenção da denominação Formação Cariri (Beurlen 1962), tendo em vista sua prioridade e utilização mais freqüente na literatura geológica.

ANÁLISE SEQÜENCIAL Sentidos de fluxo sedimentar, deduzidos a partir do mergulho das camadas frontais dos estratos cruzados, indicam paleocorrentes unimodais para norte-noroeste, notavelmente constantes ao longo da bacia, evidenciando que a geometria das áreas, onde os sedimentos estão preservados, não tem relação alguma com a geometria da bacia deposicional.

A similaridade com as paleocorrentes do Grupo Serra Grande da Bacia do Parnaíba (Bigarella 1973) permite interpretar tratos deposicionais contíguos, possivelmente com continuidade física à época da sedimentação. Nesta linha de raciocínio, 


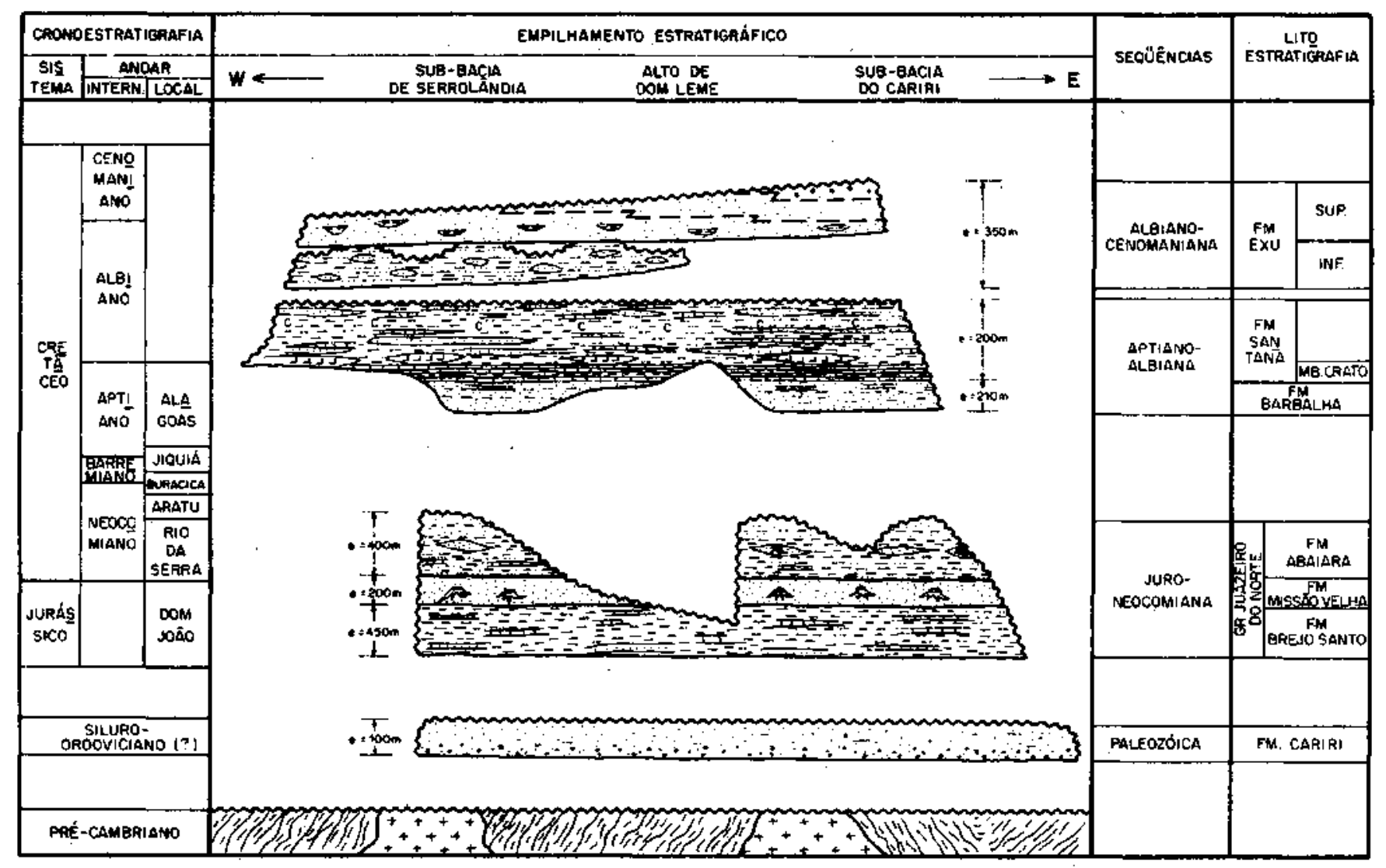

Figura 3 - Coluna estratigráfica da Bacia do Araripe (e = espessura em metros; $C$ - concreções carbonáticas fossilíferas) Figure 3 - Stratigraphic chart of Araripe Basin (e=thickness in meters; $\mathrm{C}=$ fossiliferous carbonate concretions)

os sedimentos preservados na Bacia do Araripe seriam testemunhos residuais da grande sinéclise do Pamaiba, que no Paleozóico Inferior estendia-se muito além de seu atual limite oriental, corroborando a reconstrução paleogeológica aventada por Ghignone (1972).

Seqüência Juro-Neocomiana Esta seqüência foi a resposta sedimentar à subsidência mecânica, no interior da Região Nordeste do Brasil, induzida pela transmissão no interior da placa dos esforços decorrentes dos processos de rifteamento do Gonduana.

Seus sedimentos afloram extensivamente na porção leste da bacia, ao longo do Vale do Cariri, numa sub-bacia estruturada por falhas predominantemente distensionais, de direções nordeste e leste-oeste, que definem um arcabouço em horstes e grábens (Fig. 4). Também ocorrem na porção oeste da bacia, porém apenas em sub-superficie na sub-bacia de Serrolândia, onde foi perfurado o poço 2-AP-1-CE.

Os sedimentos em questão foram incluídos por Beurlen (1962) na Formação Missão Velha, que Braun (1966) correlacionou com o Grupo Brotas da Bacia do Recôncavo. Ghignone et al (1986) verificaram que a seção sedimentar da Formação Missão Velha é muito mais espessa que os cerca de $300 \mathrm{~m}$ admitidos por estes autores, englobando também sedimentos neocomianos. Não foram, entretanto, confirmadas as presenças dos andares Buracica e Jiquiá, fato já destacado por Ponte \& Appi (1990).

Além disso, têm sido considerados como pertencentes à Formação Missão Velha, arenitos de idade aptíana superior (Moraes et al. 1976, Lima \& Perinotto 1984), superpostos em discordância angular por sobre o restante da formação. Tal discordância envolve uma lacuna no registro sedimentar correspondente ao intervalo de tempo de no mínimo do Buracica ao Alagoas inferiơr, a julgar pela não constatação de taxa destes andares. Pela existência desta discordância, que é de caráter regional, os sedimentos aptianos do topo da Formação não pertencem à seqüência juro-neocomiana, constituindo uma unidade litoestratigráfica distinta.

A Formação Missão Velha teve assim que ser redefinida. Uma opção natural seria elevar o termo à categoria de grupo, mas o mesmo é de tal forma associado na literatura geoló gica com os arenitos portadores de madeira silicificada do Andar Dom João (Brito 1987), que permaneceu restrito a eles (Ponte \& Appi 1990, Assine 1990). Para a seção pelítica basal, a denominação Formação Brejo Santo (conforme Gaspary \& Anjos 1964), emprestada da geografia local, é a mais apropriada. Para os sedimentos neocomianos foi proposta uma nova unidade, batizada de Formação Abaiara (Ponte \& Appi 1990, Assine 1990).

Ponte \& Appi (1990) propuseram também que se designasse de Grupo Vale do Cariri ao conjunto destas três formações. Todavia, como a denominação Cariri (conforme Beurlen 1962) tem sido utilizada para designar os sedimentos paleozóicos, a proposição introduz uma duplicidade de significados, sendo preferível uma outra denominação. Propõe-se, aqui, denominálo de Grupo Juazeiro do Norte, já que este município localizase na área em que a seqüência apresenta sua maior espessura.

FORMAÇÃO BREJO SANTO Constituindo a unidade basal da seqüência, é composta por folhelhos e argilitos vermelhos, sílticos, calcíferos, localmente listrados ou manchados de verde claro, entre os quais ocorrem entremeadas camadas decimétricas a métricas de arenitos finos a médios, e delgadas lâminas de calcário argiloso, rico em ostracodes, às vezes formando bancos decimetricos de puro ostracodito. Os próprios pelitos são freqüentemente ricos em carapaças destes crus- 


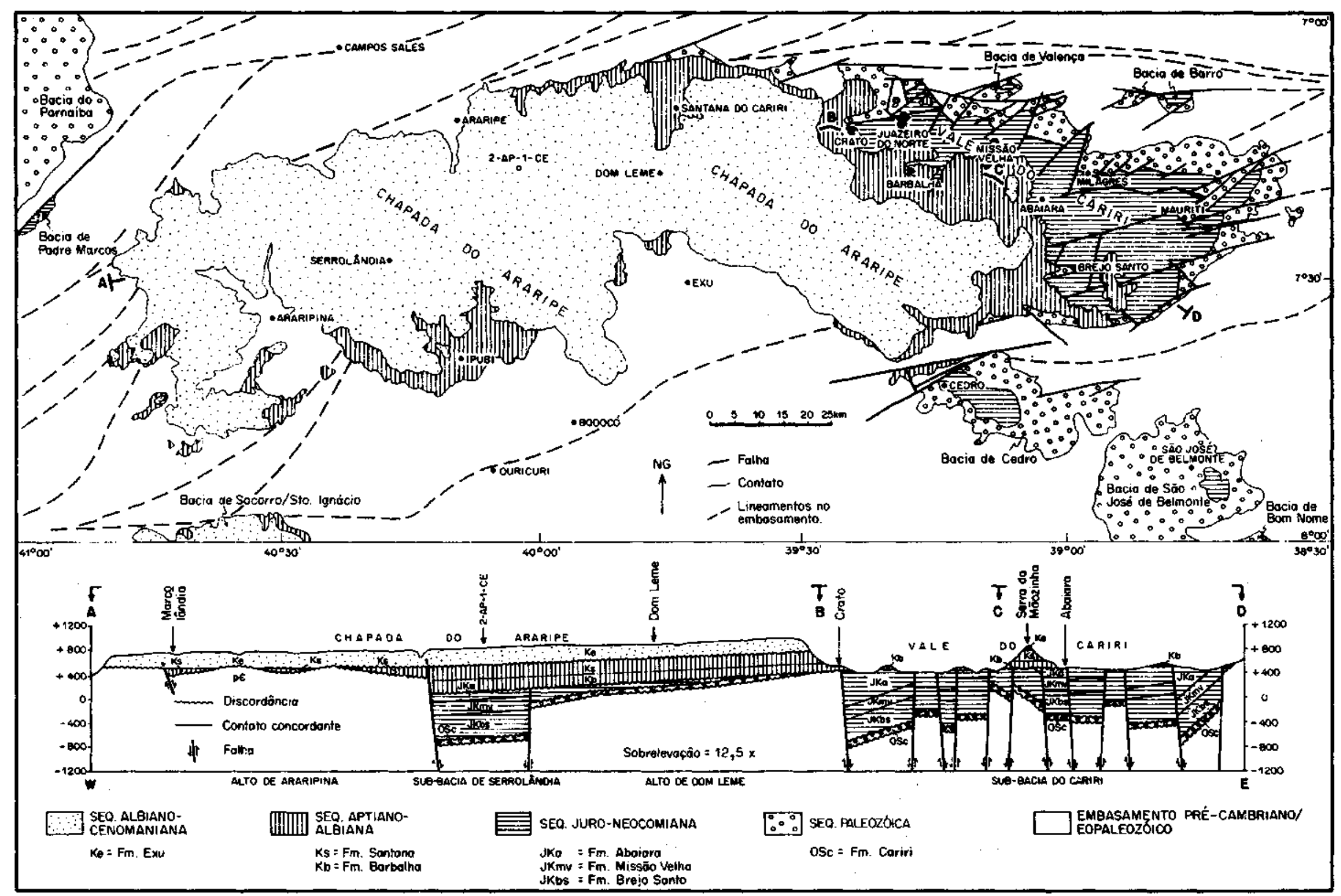

Figura 4 - Mapa geológico da Bacia do Ararípe. Na seção A-D pode ser observado o padrão estrutural em horstes e grábens das seqüências paleozóica e juro-neocomiana, e a disposição suborizontal das seqüencias aptiano-albiana e albiano-cenomaniana

Figure 4 - Geologic map of Araripe Basin. In the section A-D the horst and graben structural pattern affecting Paleozoic and Juro-Neocomian sequences may be observed, as well as the sub-horizontal display of Aptian-Albian and Albian-Cenomanian sequences 


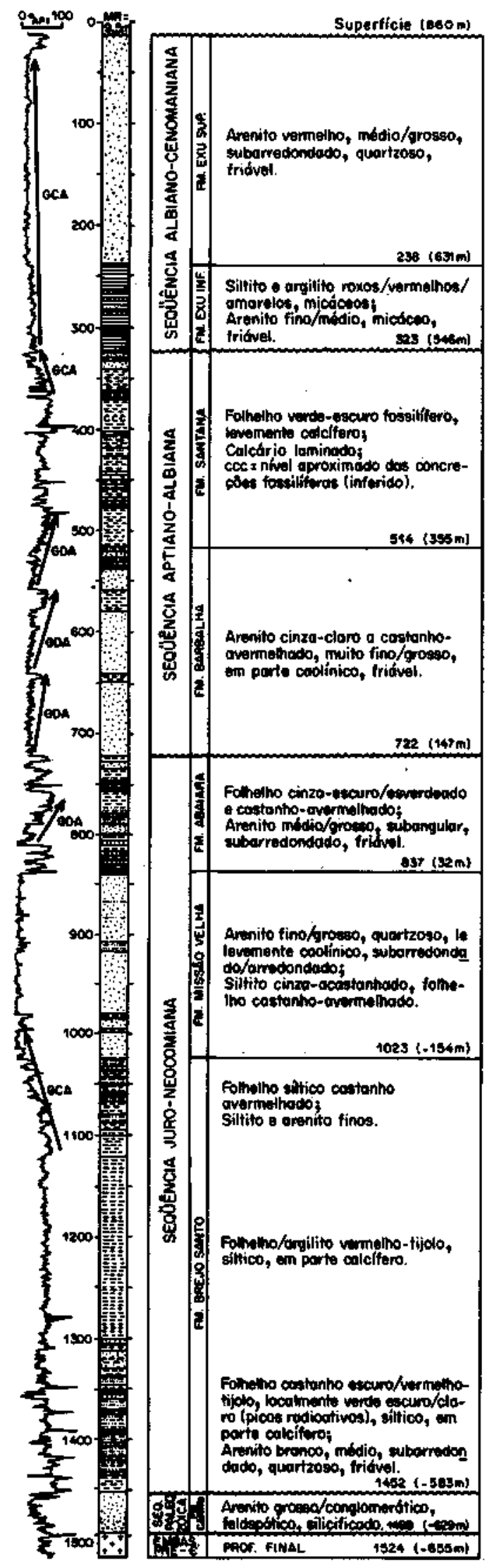

Figura 5 - Perfil estratigráfico vertical do poço 2-AP-1-CE (GDA = granodecrescência ascendente; GCA - granocrescência ascendente)

Figure 5 - Vertical stratígraphic profile of the 2-AP-1-CE well (GDA = fining upward; GCA = coarsening upward) táceos, o que os toma comumente calcíferos, achando-se presentes formas típicas do Andar Dom João, como Bisulcocypris pricei P \& S e Darwinula oblonga ROEMER, anteriormente constatadas por Braun (1966). Também comuns na associação são os restos de vertebrados, especialmente peixes, ainda não estudados.

Tais sedimentos são litológica e cronoestratigraficamente correlatos aos das Formacões Âliança da Bacia do RecôncavoTucano e Bananeiras da Bacia de Sergipe-Alagoas. Sua espessura sedimentar total é da ordem de $450 \mathrm{~m}$. Como não existem exposições contínuas na área aflorante, a seção-tipo indicada é a do intervalo 1.023 a $1.452 \mathrm{~m}$ do poç 0 2-AP-1-CE (Fig. 5).

$\mathrm{O}$ registro de formas exclusivamente não-marinhas indica sedimentação continental, em depressões amplas e rasas, onde se desenvolveram sistemas aluviais/lacustres caracterizados por condições oxidantes, ambientes propícios à formação de camadas vermelhas (red beds).

FORMAÇÃO MISSÃO VELHA A Formação Missão Velha passa a comportar única e exclusivamente os arenitos com troncos silicificados, imediatamente sobrejacentes aos folhelhos da Formação Brejo Santo. O contato entre as duas unidades é concordante, materializado por uma passagem gradual de fácies pelíticas avermelhadas para fácies psamíticas sobrepostas, que apresentam pouca variação granulométrica na vertical. Esta afirmação é exemplificada pelo padrão em caixa observado no intervalo 837 a $1.023 \mathrm{~m}$ do 2-AP-1-CE (Fig. 5), a seçãotipo da unidade. Sua espessura é de cerca de $200 \mathrm{~m}$, sendo constante ao longo da bacia.

Esta homogeneidade litológica é também observada na área de afloramento ao longo do Vale do Cariri, onde a unidade é caracterizada por arenitos quartzosos, ligeiramente feldspáticos e/ou caolínicos, às vezes conglomeráticos, portadores de abundantes troncos e fragmentos de madeira silicificada, atribuídos à conífera Dadoxilon benderi, mas ainda não descritos (Brito 1987). Os arenitos apresentam-se em sets comumente decimétricos, com estratificação cruzada predominantemente cuneiforme planar ou acanalada. Aos arenitos intercalam-se níveis descontínuos, decimétricos a métricos, de siltitos arroxeados.

O perfil estratigráfico vertical, mostrando granocrescência ascendente gradual dos pelitos avermelhados da Formação Brejo Santo para os arenitos da Formação Missão Velha, permite interpretar um empilhamento sedimentar progradante, onde lagos rasos e/ou planícies aluviais distais úmidas foram colmatadas por sistemas fluviais, através de rios entrelaçados de pequeno a médio porte, mas de alta energia a julgar pelas litologias e dimensões dos sets.

Regionalmente, são os sedimentos em questão correlatos aos das Formações Sergi da Bacia do Recôncavo-Tucano e Serraria da Bacia de Sergipe-Alagoas.

FORMAÇÃO ABAIARA No empilhamento estratigráfico vertical sobrepõe-se uma sucessão que apresenta maior variação faciológica lateral e vertical, distinguindo-se claramente dos sedimentos sotopostos, o que permitiu que fosse caracterizada como uma nova unidade litoestratigráfica. Na área de afloramento no Vale do Cariri, predominam, na base, folhelhos sílticos e siltitos vermelhos e verdes-claros, com intercalações lateralmente descontínuas de camadas decimétricas de arenitos finos e lâminas de carbonates argilosos. Para o topo, interestratificadas com folhelhos sílticos esverdeados, ocorrem lentes métricas de arenitos quartzosos finos a muito grossos, com níveis conglomeráticos, onde também se encontram fragmentos de madeira silicificada.

Compõe o quadro final arenitos finos a médios, subarredondados, em sets decimétricos a métricos, com estratificação cruzada tabular tangencial na base, sendo comuns estruturas convolutas formadas por deformação penecontemporânea. Nestes arenitos, intercalam-se alguns poucos níveis decimétricos a métricos de folhelhos papiráceos, freqüentemente fos- 
silíferos, com escamas de peixes, mas sobretudo portadores de ostracodes, em geral muito recristalizados.

A presença de ostracodes como Cypridea sellata VIANA e Cypridea candeiensis KRO permitiu posicionar cronoestratigraficamente a unidade no Andar Rio da Serra (biozonas RT002 e RT-003 de Viana et al. 1971). A constatação de outras espécies, como Cypridea vulgaris, e sugestiva de continuidade da sedimentação até o Andar Aratu.

Como seção-tipo da Formação Abaiara, propõe-se a que é observada na estrada de acesso a Abaiara, a partir da rodovia que liga Juazeiro do Norte à rodovia BR-116 (Fig. 6). No poço 2-AP--CE, a espessura da unidade é de apenas $115 \mathrm{~m}$, sendo os sedimentos caracterizados litologicamente por intercalações de folhelhos cinza-escuros e arenitos médios a grossos. Espessuras maiores são inferidas entre Crato e Juazeiro do Norte, a partir de dados sísmicos.
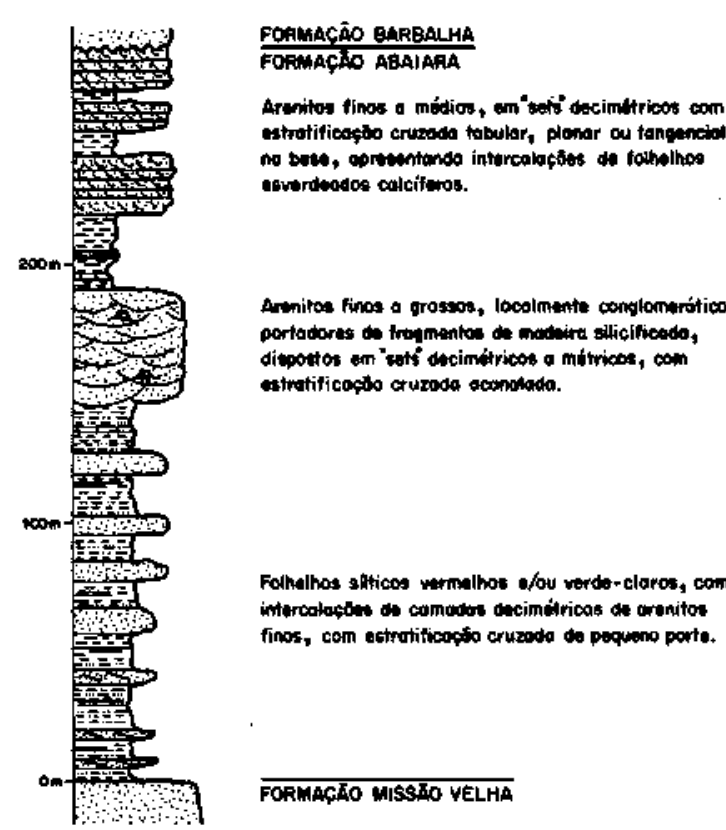

aciserdecos calcifuros.
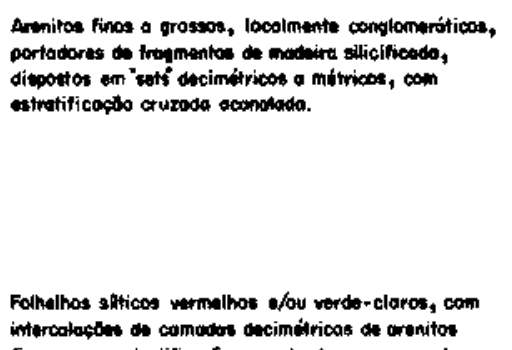
finos, com ectrotificapto cruzodo de pequeno porte.

FORMAGLO MISSRO VELHA

Figura 6 - Seção-tipo da Formação Abaiara; estrada de acesso a Abaiara, a partir da rodovia que liga Juazeiro do Norte à rodovia BR-116

Figure 6 - Type-section of Abaiara Formation; access road to Abaiara, starting from the main road connecting Juazeiro do Norte to BR-116 highway

Os sedimentos da Formação Abaiara são também de origem continental, patenteando no andar Rio da Serra a permanência dos mesmos tratos deposicionais do Andar Dom João. Os folhelhos e siltitos de tonalidades avermelhadas presentes na base do Andar Rio da Serra são interpretados como produto de sistemas lacustres rasos/planícies aluviais, em direção ao topo sendo sucedidos por arenitos fluviais. Os folhelhos esverdeados e os biosparitos (ostracodes), entremeados aos arenitos, são 0 registro de lagos efềmeros adjacentes aos canais, originados nas várzeas como conseqüência de inundações. Constituíam subambientes de baixa energia, onde os ostracodes se desenvolveram abundantemente.

ANÁLISE SEQÜENCIAL A seqüência juro-neocomiana patenteia sedimentação essencialmente continental, com recorrências de sistemas fluviais e lacustres de pequena profundidade. A polaridade sedimentar, deduzida a partir das fácies fluviais, permaneceu aproximadamente constante, tendo a ba- cia mergulho deposicional para sul, integrando uma paleodrenagem continental que fluía em direção à Bacia do RecôncavoTucano. Não existem dados que permitam concluir que constituíam tratos deposicionais contínuos, todavia, a extensão original da seqüência era muito maior do que as áreas onde hoje os sedimentos estão preservados, havendo testemunhos residuais em pequenas bacias adjacentes à do Araripe, como as de Barro, Cedro e Mirandiba.

Seus limites atuais são, na maioria das vezes, definidos por falhas. Não foram constatadas evidências de tectônica sindeposicional, tais como estruturas sindeformacionais ou fanglomerados associados aos blocos baixos das falhas limítrofes. Por isso, a estruturação dos sedimentos desta seqüência, também observada na seqüência paleozóica, é interpretada como produto de eventos de tectônica deformadora, atuante no intervalo Neocomiano superior/Barremiano.

Seqüência Aptiano-Albiana Esta seqüência, constituída pelas Formações Barbalha e Santana, ocorre em quase toda a extensão da Chapada do Araripe e, descontinuamente, ao longo do Vale do Carüi Distingue-se estrutural e estratigraficamente das duas seqüências sotopostas, sobre as quais assenta-se em discordância angular. Na porção ocidental da bacia, é comum repousar diretamente sobre o embasamento pré-cambriano/eopaleozóico.

FORMAÇÃO BARBALHA Unidade basal, é constituída predominantemente de fácies arenosas com intercalações de lamitos avermelhados e amarelados, e de níveis delgados de conglomerados. Os arenitos são finos a médios, subarredondados a subangulares, em geral bastante friáveis, argilosos e micáceos, às vezes seixosos e/ou portadores de feldspatos caulinizados e bolas de argila. A estratificacão é cruzada, de médio a pequeno porte, tabular planar ou tangencial na base, comparecendo também feições sigmoidais.

Tais sedimentos apresentam-se em ciclos com granodecrescência ascendente que culminam em intervalos pelíticos, cuja assinatura em perfil raios-gama pode ser observada no intervalo 480 a $722 \mathrm{~m}$ do poço 2-AP-l-CE (Fig. 5). São interpretados como fluvio-lacustres, não só pelas litologias e estruturas sedimentares, mas pela presença de fósseis continentais.

Nos afloramentos situados no sopé das escarpas da chapada, voltadas para o Vale do Cariri, verifica-se quase que invariavelmente que um dos ciclos se encerra com um intervalo de folhelhos pirobeturninosos pretos, ricos em laminações carbonáticas algálicas, coprólitos, ostracodes, restos de peixes (Dastilbe elongatus) e fragmentos vegetais carbonizados. Sua idade é aptiana superior, obtida a partir da análise de palinomorfos (Farina 1974, Lima \& Perinotto 1984, Hashimoto et al. 1987). Este intervalo, em meio ao qual se encontra uma camada decimétrica de calcário com aspecto brechóide e mineralizada em sulfetos, foi denominado "seqüência plumbíferado Araripe", por Farina (1974) e "camadas Batateira" por Hashimoto et al. (1987).

As "camadas Batateira" representam o final de um evento de redução paulatina da energia do ambiente fluvial, constituindo o primeiro registro de um amplo sistema lacustre na seqüência. Inicialmente restrito e caracterizado por águas rasas e pouco oxigenadas (Eh redutor), constituiu o ambiente propício à fixação de íons metálicos ( $\mathrm{Pb}, \mathrm{Zn}$ e $\mathrm{Cu})$ sob a forma de sulfetos, cuja precipitação foi favorecida pela alta porosidade das brechas carbonaticas.

Os sedimentos em questão faziam parte do topo da Formação Missão Velha de Beurlen (1962). Como discutido anteriormente, devido existência de uma discordância de caráter regional no seio daquela unidade, ficou caracterizada a existência de uma nova unidade. Já que a denominação Batateira, utilizada por Ponte \& Appi (1990), havia sido anteriormente utilizada por Hashimoto et al. (1987) para destacar o intervalo de folhelhos pirobetuminosos e brechas carbonáticas, um marco 
estratigráfico de importância regional, é proposta a utilização da denominação Formação Barbalha (Assine 1990) para a unidade, cuja seção-tipo (Rg. 7) pode ser observada no Rio Batateiras, entre a cidade de Grato (CE) e as escarpas da Chapada do Araripe.

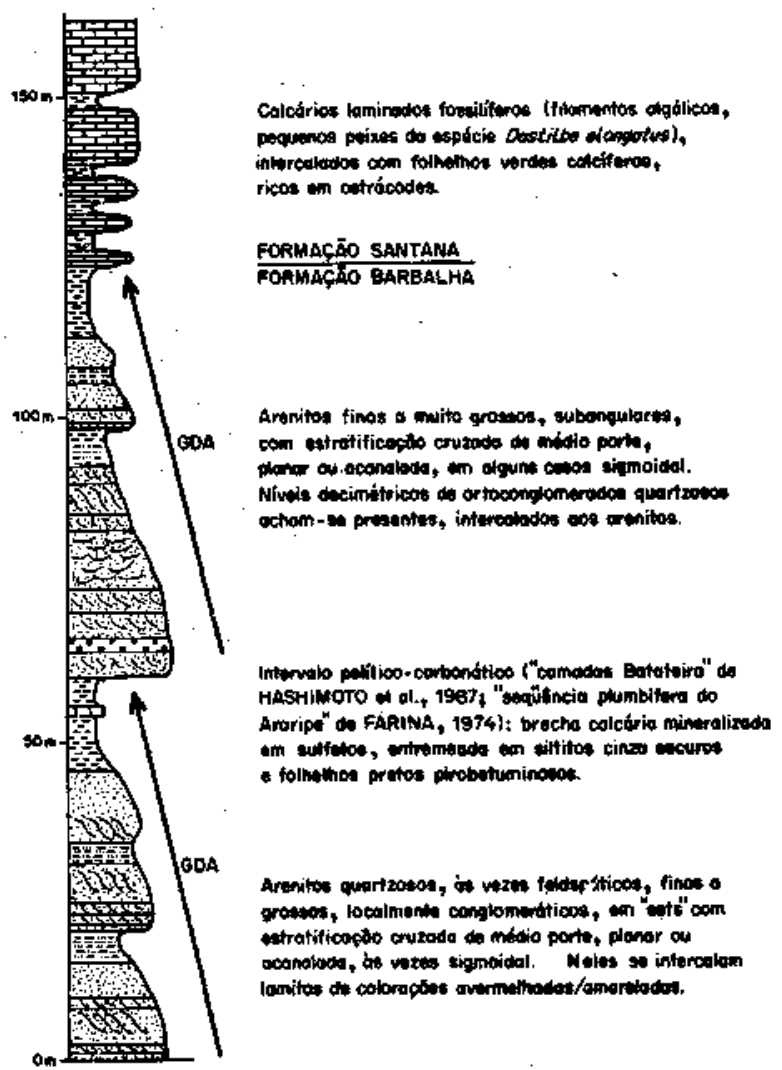

Figura 7 - Seção-tipo da Formação Barbalha; Rio Batateiras, oeste de Cràto (GDA = granodecrescência ascendente) Figure 7 - Type-section of Barbalha Formation; Batateiras River, west Crato (GDA = fining upward)

A não-caracterização anterior da discordância como tal é conseqüência da similaridade litológica das litologias superpostas. Entretanto, ainda que macroscopicamente semelhantes aos arenitos das formações Missão Velha e Abalara, a existência de intercalações de folhelhos cinza-escuros a pretos e o caráter mais friável dos arenitos da Formação Barbalha, são critérios que permitem distinguir estes sedimentos daqueles. Critérios estruturais constituem elementos adicionais na identificação da Formação Barbalha, que pode ser reconhecida dentro do próprio Vale do Cariri, onde ocorre sob a forma de tabuleiros suborizontalizados recobrindo sedimentos juro-neocomianos, estes na maioria das vezes também arenosos, mas freqüentemente estruturados tectonicamente em blocos basculados.

FORMAÇÃO SANTANA Culminando o último ciclo granodecrescente da Formação Barbalha, numa passagem gradual, tem-se uma seção de folhelhos papiráceos calcíferos, interestratificados com calcários micríticos laminados, formando extensos bancos com espessuras de até mais de duas dezenas de metros. Folhelhos pirobetuminosos com teores de até 25\% de carbono orgânico total, e freqüentemente calcíferos devido a abundância de carapaças de ostrácodes, continuam presentes. $\mathrm{O}$ registro fossilífero é abundante, sendo também encontrados conchostráceos, fragmentos vegetais lenhosos carbonizados, além de pequenos peixes (Dastilbe elongatus) e insetos (Mabesoone \& Tinoco 1973, Martins 1990).

Esta seção pelítico-carbonática, que caracteriza a parte inferior da Formação Santana e que tem sido referida como Membro Cratp (Beurlen 1962), atesta a ampliação dos sistemas lacustres, indicando condições de baixa energia no ambiente deposicional, com influxo terrígeno e turvação da água paulatinamente decrescentes, sendo comum nos carbonates a presença de filamentos algálicos.

Por sobre os calcários laminados, em associação com folhelhos verdes e/ou pretos (pirobetuminosos), acham-se presentes evaporitos. Estes apresentam pouca variabilidade química, restringindo-se a sulfates de cálcio, principalmente sob a forma de gipsita laminada primária com cristais colunares dispostos em paliçadas (palisades). Esta laminação, interna às camadas de gipsita, apresenta-se muitas vezes dobrada irregularmente, formando feições semelhantes a domos. Petrograficamente, os evaporitos foram analisados em detalhe por Silva $(1983,1988)$, que descreveu também ocorrências de pseudomorfos de gipsita lenticular, anidrita laminada e nodular. Gipsita secundária é representada pelas variedades alabastro, porfiroblástica (rosetas de gipsita incolor) e nodular. Variedades fibrosas constituem a última geração, sendo produto de recristalização a partir de soluções ricas em sulfato de cálcio, mobilizadas nos processos de diagênese.

Com espessura máxima da ordem de 30 metros, as camadas de gipsita são lenticulares e lateralmente contíguas a folhelhos cinza-esverdeados, carbonates ou mesmo arenitos. Embora bastante comuns na área de Santana do Cariri (CE), concentram-se sobretudo na porção oeste da bacia, de Ipubi a Araripina (PE). Na região nordeste da Chapada, adjacente ao Vale do Cariri, as lentes são ocasionais, correspondendo em tempo a uma seção de folhelhos verdes com delgadas camadas de arenitos finos e calcários laminados, onde Silva (1986a) descreveu níveis de caliche.

A descontinuidade das camadas (lentes), a presença tão somente de sulfates, a existência de folhelhos entremeados portadores de conchostráceos, e a presença marcante de folhelhos pirobetuminosos pretos ricos em ostrácodes não-marinhos e fragmentos vegetais carbonizados, evidenciam anão existência de uma bacia evaporítica marinha ampla e contínua. Tampouco a bacia era exclusivamente continental, pois a associação paleontológica inclui também formas marinhas nos estratos associados (Lima 1978a).

Os evaporitos são interpretados como originados em ambientes costeiros (supramaré), sujeitos a variações relativas do nível do mar, em condições de clima árido a semi-árido. As características mineralógicas, dimensões, natureza e geometria dos jazimentos indicam sistemas deposicionais similares aos das modernas salinas do sul da Austrália. Estas constituem ambientes costeiros subaquosos, sem conexão com o mar, com dimensões individuais da ordem de dezenas a centenas de quilômetros quadrados, preenchidas por gipsita laminada com espessuras que ultrapassam uma dezena de metros (Warren \& Kendall 1985).

A interação de processos subaquosos e subaéreos conduziu à grande complexidade faciológica deste intervalo, caracterizado pela interdigitação de sedimentos portadores de fósseis de origem continental e marinha (Lima 1978a). As variações faciológicas, tanto de litofácies quanto de biofácies, podem ser observadas claramente nas diferentes minas de gipsita existentes na região. Próximo à Santana do Cariri $(\mathrm{CE})$, por exemplo, em duas minas não mais distantes que $500 \mathrm{~m}$ uma da outra, encontram-se desde folhelhos pirobetuminosos pretos, portadores de peixes fósseis e outros produtos de derivação orgânica descritos por Viana et al. (1989), e calcários laminados com madeiras carbonizadas, até arenitos lenticulares.

Assentando-se diretamente sobre as camadas de gipsita, tais arenitos são conglomeráticos na base, apresentando nítido 
padrão de afinamento textural para o topo. São fácies de canais fluviais, indicativas de fluxos torrenciais episódicos em meio ao ambiente de aridez em que a precipitação dos evaporitos tinha lugar. Acham-se presentes, também, lamitos verdes calcíferos que apresentam fósseis não marinhos, como ostracodes de água doce (Berthou et al. 1988).

Na parte oeste da bacia é comum a presença de folhelhos calcíferos esverdeados ou avermelhados. Na mina de Lagoa de Dentro, em Araripina (PE), acima dos evaporitos, há uma sucessão de folhelhos, arenitos e carbonates com estruturas sedimentares indicativas de retrabalhamento por ondas.

Alguns metros acima do topo dos evaporitos ocorre o principal jazigo paleontologia) do Araripe, constituído por abundantes concreções carbonáticas, freqüentemente fossilíferas, que ocorrem em meio à fácies de folhelhos calcíferos esverdeados, ricos em ostracodes. Grande parte destas concreções encerra peixes em seu interior, num total de 18 espécies, compondo uma paleoictiofauna considerada marinha (Silva Santos \& Valença 1968). Também são encontrados, entre outros vertebrados, dinossauros (Leonardi \& Borgomanero 1981), tartarugas marinhas (Price 1973) e pterossauros (Price 1971, Campos \& Kellner 1985).

Petrograficamente, as concreções são constituídas por calcário micrítico argiloso, finamente laminado, concordante com o acamamento dos folhelhos verdes nos quais estão alojadas, sendo marcante a presença de ostracodes articulados, constituindo comumente biomicritos cimentados por calcita espática. Segundo Martill (1988), as características da preservação dos peixes nas concreções (pequenas escamas e barbatanas articuladas) indicam águas muito calmas, estando a causa da mortandade em massa destes organismos nectônicos associada a uma mudança catastrófica da química (flutuação da salinidade) ou da temperatura nas águas superficiais.

A presenca de moluscos tidos como marinhos (Beurlen 1963), dinoflagelados e foraminíferos (Lima 1978a, Arai \& Coimbra 1990), e principalmente equinóides (Beurlen 1966) confirmam inquestionável ingressão marinha na área. A reconstrução paleogeográfica à época desta ingressão ainda está por ser feita, requerendo estudos estratigráficos e paleoecológicos detalhados. Uma interessante tentativa é a de Santos (1982), que atribuiu as variações lito e biofaciológicas à dinâmica de planícies de maré carbonáticas.

Para o topo, interdigitados aos sedimentos pelítico-carbonáticos portadores de fósseis marinhos, paulatinamente voltam a ocorrer siltitos e arenitos com fósseis de água doce, como conchostráceos e moluscos (Beurlen 1971).

Geocronologicamente, a Formação Santana é posicionada no Aptiano Superior/Albiano Inferior. Há, entretanto, divergências quanto à cronoestratigrafia. Com base em palinomorfos, Regali (1989) considera os evaporitos de idade aptiana superior, enquanto Lima (1978a) atribui idade albiana inferior para toda a formação.

A subdivisão interna da Formação Santana em membros Crato, Ipubi e Romualdo (Beurlen 1971), não é inteiramente factível, fato já destacado por Lima (1979), pois foi baseada em critérios ambientais (bioestratigráficos ou paleoecológicos), e não em bases litoestratigráficas. À exceção do Membro Crato, os membros superiores (Ipubi e Romualdo) constituem, mais apropriadamente, associações de biofácies, freqüentemente recorrentes no empilhamento sedimentar. Além disso, é comum a utilizacão dos termos em desacordo com a proposta original de Beurlen (1971), tanto que Mabesoone \& Tinoco (1973) colocam o nível de folhelhos com concrecões carbonáticas fossilíferas dentro do Membro Romualdo, quando pela definição pertenceriam ao Membro Ipubi.

ANÁLISE SEQÜENCIAL Pela sucessão vertical de fácies descrita, cujo formato em perfis pode ser visualizado nos registros do poco 2-AP-1-CE (Fig. 5), verifica-se que o empilhamento estratigráfico mostra um marcante afinamento tex- tural para o topo a partir dos arenitos continentais da base da seqüência (Formação Barbalha), que, paulatinamente, apresentam mais e mais intercalações de pelitos. A argilosidade continua aumentando até uma superfície de máxima inundação marinha (maximum marine-flooding surface), situada na profundidade de $400 \mathrm{~m}$ do 2-AP-l-CE (Fig. 5). Tal superfície corresponde à máxima transgressão, momento em que o mar mais avançou continente adentro, atingindo áreas até então não abrangidas pela bacia, ocorrendo deposição de folhelhos diretamente sobre o embasamento na porção oeste da bacia. A superfície de máxima transgressão está situada aproximadamente ao nível dos folhelhos esverdeados portadores de concreções carbonáticas fossilíferas, que registram eventos de mortandade em massa.

Em direção ao topo, a partir desse ponto, voltam a predominar condições continentais, dedutíveis pelo padrão de engrossamento textural ascendente e pela presença de fósseis nãomarinhos. Este padrão vertical, observado tanto em superficie quanto em subsuperficie, corresponde aproximadamente à evolução paleoambiental anteriormente relatada por Beurlen (1971) e Lima (1978a,c).

A análise faciológica e seqüencial da Formação Santana indica, sob a ótica da ordem de grandeza da seqüência considerada, que a sedimentação foi contínua, sem hiatos deposicionais de grande expressão. As feições paleocársticas no topo dos evaporitos e níveis de caliche descritos por Silva (1986a), não implicam necessariamente em discordância, podendo ser uma simples feição resultante de exposições subaéreas com retrabalhamento. Segundo Warren (1982), as modernas salinas australianas, tornadas como modelo deposicional, são expostas subaereamente com muita freqüência, sendo comum a completa evaporação das águas nos verões.

Sustenta esta interpretação o fato de não existirem evidências palontológicas significativas de discordância, como pode ser verificado pelos dados palinológicos apresentados por Lima (1978a). Descontinuidades menores são comuns no registro sedimentar, e muitas outras existem dentro da própria Formação Santana. Diversas parasseqüências podem ser identificadas dentro da unidade, conseqüências de variações menores no nível relativo do mar ou de flutuação no afluxo sedimentar, mas uma análise seqüencial refinada ainda está por ser feita. Estas flutuações são as responsáveis pela interdigitação de fácies marinhas e não-marinhas (Lima 1978a), comum em ambientes costeiros como os da Formação Santana, onde os efeitos da variação das marés eram sobremaneira acentuados (Santos 1982).

Com base nestas considerações, não foi adotada a subdivisão de Silva (1986a,b), que subtraiu da Formação Santana sua metade inferior, sob a denominação Formação Araripina. Além disso, a denominação Formação Santana para todo o pacote está consagrada na literatura geológica internacional, e a sua manutenção com esse significado é desejável.

A seqüência compreende, portanto, um ciclo transgressivoregressivo quase completo, com ingressão marinha de curta duração, cujo sentido é matéria de muitas controvérsias. A sedimentação original era muito mais extensa, sendo testemunho mais notável deste fato, a existência de sedimentos correlates na Serra Negra, Bacia de Tucano-Jatobá, alçados a cotas altimétricas similares às da Chapada do Araripe.

Paleocorrentes fluviais medidas na Formação Barbalha, unidade basal e correlata à Formação Matizai da Bacia do Recôncavo-Tucano, revelaram paleofluxo para sudeste. Isto indica que os eventos tectônicos do final do Cretáceo inferior não alteraram significativamente a paleodrenagem continental da época, que, da região da Bacia do Araripe, fluía em direção à Bacia do Recôncavo-Tucano e, possivelmente, Sergipe-Alagoas.

Seqüência Alblano-Cenomaniana Os sedimentos desta seqüência pertencem a uma única unidade litoestratigráfica, denominada Formação Exu (Beurlen 1962). Seu contato 
com a seqüência aptiano-albiana é de difícil observação no campo, conseqüência da presença constante de depósitos de tálus nas escarpas da Chapada do Ararípe. Duas evidências, entretanto, sustentam a interpretação de um contato discordante entre as mesmas, ainda que de curta dura-ção. No registro paleontológico, Lima (1978b) constatou falta de seção correspondente à parte do Albiano Inferior a médio, entre a Formação Santana e o membro inferior da Formação Exu.

Estruturalmente, os sedimentos da Formação Santana apresentam-se tectonicamente movimentados, embora localmente, como nas minas de Lagoa de Dentro e Rancharia, a sul de Araripina (PE), onde toda a formação apresenta-se basculada, assim como o próprio embasamento, evidenciando uma tectônica deformadora pós-sedimentar. De baixa intensidade, o evento, que prolongou-se até a época de deposição dos sedimentos basais da Formação Exu, caracterizou-se pela reativação de linhas de fraqueza do embasamento pré-cambriano/ eopaleozóico, sobretudo na porção oeste da bacia, onde se dá a terminação do lineamento de Patos, com deflexão das estruturas para sudoeste.

De natureza essencialmente terrígena, a seqüência é praticamente afossilífera. Lima (1978a,b) é o único a datá-la (Albiano Médio) com base em palinomorfos, encontrados em sua porção basal. A idade obtida representa, entretanto, apenas o início da sedimentação, não sendo disponíveis, até o presente, dados que permitam definir a idade dos estratos superiores. A julgar pelos sedimentos cronocorrelatos das bacias adjacentes, como os das Formações Açu (Bacia Potiguar) e Itapecuru (Bacia do Parnaíba), a sedimentação prolongou-se até o Cenomaniano.

Mabesoone \& Tinoco (1973) constataram que a Formação Exu, na porção oeste da bacia, compõem-se de dois membros com características litológicas diferentes, denominando-os informalmente de membros inferior e superior. $\mathrm{O}$ contato entre eles é marcado por brusca mudança litológica e, pelo menos localmente, descontinuidades de natureza erosiva.

FORMAÇÃO EXU INFERIOR Restrita à porção oeste da bacia, constitui-se de uma associação de fácies heterolíticas, caracterizada por grande diversidade de litótipos, recorrentes e geneticamente relacionados. Ritmitos argilo-siltosos de colorações avermelhadas, arroxeadas e amareladas, com laminaçãp plano-paralela, constituem a principal fácies presente. Disponibilidade de fração areia muito fina resulta em acamamento lenticular (linsen) e ondulado (wavy), ou mesmo constitui níveis de arenitos argilosos finos a muito finos, que se apresentam em camadas centimétricas a decimétricas, com laminação cruzada cavalgante (climbing ripple cross-lamination). Quando sobrepõem litologias argilosas, geram estruturas de sobrecarga como pseudonódulos e almofadas e estruturas em chama. Aos ritmitos associam-se, também, arenitos em que predominam as frações areia fina a média, dispostos em corpos de geometria lenticular, com espessuras variando de alguns centímetros a alguns metros.

Uma característica marcante é a presença freqüente de truncamentos na estratifícação, constituindo diastemas angulares internos à unidade. São interpretados como gerados durante a sedimentação, produto de tectônica sindeposicional. Em alguns intervalos, os ritmitos podem apresentar-se com dobramentos convolutos, por deformação penecontemporânea. Em outros, apresentam-se rompidos formando brechas intraformacionais, com contatos erosivos por sobre as litologias subjacentes.

Os sedimentos da associação heterolítica são interpretados como depositados em planícies distais de leques aluviais, onde a área efetiva de sedimentação permaneceu freqüentemente saturada de água, de forma que feições de exposição, tais como gretas de ressecação, não são comuns. Os ritmitos são interpretados como produto de fluxo laminar não confinado (sheetflood), com transporte predominantemente por suspensão nos períodos de aumento da descarga fluvial. Os arenitos lenticulares representariam fácies de canais distributaries, que progressivamente se dissipariam nas porções distais, conseqüência de diminuição da declividade.

FORMAÇÃO EXU SUPERIOR Sobreposta às fácies heterolíticas do membro inferior, a associação de fácies psamíticas da Formação Exu superior registra o recobrimento das planícies aluviais argilosas, freqüentemente úmidas, por sedimentos tipicamente fluviais. Apresentando-se em ciclos com granodecrescência ascendente, dados por níveis seixosos na base seguidos de arenitos grossos com estratifícação cruzada tabular a acanalada e dispostos em sets decimétricos a métricos, em meio aos quais ocorrem fácies lamíticas de planície de inundação, os sedimentos em questão são interpretados como produtos de rios meandrantes. No entanto, a pobreza em fácies de planície de inundação não coaduna com o modelo meandrante pelítico comumente descrito na literatura geológica. Enquadra-se melhor no modelo meandrante psamítico apresentado por Fisher \& Brown (1972).

Na porção leste da bacia, as características litológicas e texturais dos arenitos, que apresentam, em geral, granulometria média a grossa, muitas vezes conglomerática, e estratificações cruzadas tubulares e acanaladas, são compatíveis com o modelo fluvial entrelaçado.

ANÁLISE SEQÜENCIAL Na seqüência, o perfil vertical denota granocrescência ascendente, refletindo o aumento da energia de transporte, fenômeno que se repete também na horizontal, com aumento da granulometria na direção leste, onde não mais estão presentes as fácies heterolíticas, numa variação faciológica regional indicativa de área-fonte situada para além dos limites orientais da bacia. Corrobora esta interpretação o padrão geral de paleocorrentes para oeste-sudoeste, deduzido a partir de medidas das camadas frontais dos arenitos do membro superior.

A existência de contatos erosivos entre as duas unidades, sob a forma de grandes canais, não necessariamente corresponde a hiato de tempo significativo que caracterize uma discordância bacinal. Tais feições podem ser resultado, não só de entalhe provocado por mudanças no nível de base da drenagem fluvial (processos alocíclicos), mas da migração lateral dos próprios canais fluviais (processos autocíclicos), no processo de assoreamento fluvial das depressões onde ocorria a deposição das fácies heterolíticas.

Enquanto a seqüência aptiano-albiana materializa um ciclo transgressivo-regressivo, reflexo de eventos eustáticos globais de elevação do nível do mar no Cretáceo, os sedimentos fluviais desta seqüência, depositados ainda em condições eustáticas positivas, evidenciam um soerguimento epirogênico da região já a partir do Albiano Médio/Superior. Isto causou um rearranjo da paleodrenagem continental, que então passou a fluir para oeste, em direção à Bacia do Pamaíba, integrando tratos deposicionais contíguos aos da Formação Itapecuru daquela bacia.

CONCLUSÕES O registro sedimentar da Bacia do Araripe é caracterizado por quatro seqüências estratigráficas limitadas por discordâncias. As quatro seqüências denotam embaciamentos distintos, dos quais somente uma fração da cobertura original está presente, não havendo porções marginais e depocentros definidos. Este registro fragmentário, no espaço e no tempo, dificulta a compreensão da evolução geológica da bacia, que no Fanerozóico integrou contextos geotectônicos e paleogeográficos diversos.

A seqüência paleozóica (Formação Cariri) constitui-se quase que exclusivamente de arenitos. Por serem afossilíferos, muitas são as dúvidas quanto à sua cronoestratigrafia. Tentativamente, foi atribuída uma idade siluro-ordoviciana, por correlação com os sedimentos da base do Grupo Serra Grande da Bacia do Pamaíba, com os quais possivelmente tinham continuidade física à época da sedimentação. 
A sequiência juro-neocomiana é constituída pelas Formações Brejo Santo, Missão Velha e Abaiara. Para o conjunto das três, é proposta a denominação Grupo Juazeiro do Norte. Tais unidades são a resposta sedimentar à subsidência mecânica localizada, decorrente dos processos de rifteamento do Gonduana. De natureza rúptil, a principal fase tectônica ocorreu do Neocomiano Superior ao Barremiano, atuando principamente como evento deformador, responsável pela disposição dos sedimentos juro-neocomianos em horstes e grábens. Este estilo tafrogênico, que envolveu também os sedimentos paleozóicos subjacentes, foi responsável pela compartimentação em duas sub-bacias: Cariri e Serrolândia.

A seqüência aptiano-albiana assenta-se sobre as duas inferiores em discordância angular. Iniciando-se com os arenitos fluviais da Formação Barbalha, aos quais se sobrepõe a seção pelítico-evaporítico-carbonática da Formação Santana, constitui um ciclo transgressi vo-regressi vo quase completo. A transgressão marinha foi de curta duração e conseqüência dos eventos eustáticos globais de elevacão do nível do mar no Cretáceo, cujo máximo somente foi atingido no Turoniano.
$\mathrm{O}$ brusco retomo às condições continentais reinantes durante a sedimentação da seqüência albiano-cenomaniana, depositada ainda em condiçôes eustáticas globais positivas, evidência um soerguimentp epirogênico diferenciado da Região Nordeste do Brasil, já a partir do Albiano Médio/Superior. Um basculamento para oeste, onde se situam as porcões distais das planícies fluviais da Formação Exu, foi inferido a partir da distribuição espacial das fácies sedimentares e padrão geral de paleocorrentes.

Agradecimentos $\mathrm{O}$ autor externa seus agradecimentos aos professores Dr. Ercílio Gama, pela orientação duran-te a realização do mestrado, Dr. Chang Hung Kiang, pelo apoio em diferentes etapas do trabalho, e Dr. Setembrino Petri, pela leitura crítica do texto e sugestões apresentadas; à estudante Maria Cristina de Souza (bolsista PET/CAPES) pela edição do texto; ao desenhista Oto Laurentinon Rosa, pelas ilustrações; ao colega João Carlos ^ ${ }^{\wedge}$ Coimbra pelas análises paleontológicas e à PETROBRÁS pelo apoio financeiro.

\section{REFERÊNCIAS BIBLIOGRÁFICAS}

ARAI, M. \& COIMBRA, J.C. 1990. Análise paleoecológica do registro das primeiras ingressões marinhas na Formação Santana (Cretáceo Inferior, Chapada do Araripe). In: SIMP. BACIA DO ARARIPE E BACIAS INTERIORES DO NORDESTE, 1. Grato, 1990. Anais... Crato, DNPM/ SBP/SBG. p. 225-239.

ASSINE, M.L. 1990. Sedimentação e Tectônica da Bacia do Araripe, Nordeste do Brasil. Rio Claro. 124 p. (Dissertação de Mestrado, IGCE/ UNESP).

BARROS, F.C. 1963. Sobre a sistemática da Série do Araripe. Rev, Eng. Min. Metal, 218:52.

BERRY, W.B.N. \& BOUCOT, A.J. 1972. Correlation of the South American Silurian Rocks. USA, Geol. Soe. Amer. 59 p. (Special Paper 133).

BERTHOU, P.Y.; DEPEHCES, K; CAMPOS, D.A.; HEREIN, J.P PIERRES, C. 1988. New data on sedimentation, paleoenvironment and stratigraphy of the Chapada do Araripe. Rev. Bras. Geoc., 18(3):315.

BEURLEN, K. 1962. A geologia da Chapada do Araripe. An. Acad. bras Cienc., 34(3):365-370

BEURLEN, K. 1963. Geologia e estratigrafia da Chapada do Araripe. In: CONOR. BRAS. GEOL., 17. Recife, 1963. Anais... Recife, SBG/ SUDENE. 47 p. (Suplemento).

BEURLEN, K. 1966. Novos equinóides no Cretáceo do Nordeste do Brasil An. Acad bras. Cienc., 389(3/4):455-464.

BEURLEN, K. 1971. As condições ecológicas e faciológicas da Formação Santana na Chapada do Araripe (Nordeste do Brasil). An. Acad. bras. Ctónc.,43(supl.):411-415.

BIGARELLA, JJ. 1973. Paleocorrentes e deriva continental (comparação entre América do Sul e África). Boi Parem. Geoc., 31:141-224.

BRAUN, O.P.G. 1966. Estratigrafia dos Sedimentos da Parte Inferior da Região Nordeste do Brasil (Bacias do Tucano-Jatobá, Mirandiba e Araripe). Rio de Janeiro, DNPM/DGM. 75 p. (Boletim 236).

BRITO, LM. 1987. As unidades litoestratigráficas da passagem JurássicoCretáceo do Nordeste do Brasil. Rev.Bras.Geoc., 17(2):81-85.

CAMPOS, D.A.\& KELLNER, A.W.A. 1985. Panorama of the flying reptiles study in Brazil and South America. An. Acad. bras. Cienc. 57(4):453-466.

CAPUTO, M.V. \& CROWELL, J.C. 1985. Migration of glacial centers across Gondwana during Paleozoic Era. Geol. Soc. Amer. Bull, 96:1020-1036.

CAPUTO, M.V. \& LIMA. E.C. 1984. Estratigrafia, idade e correlação do Grupo Serra Grande - Bacia do Pamaíba. In: CONOR. BRAS GEOL., 33. Rio de Janeiro, 1984. Anais... Rio de Janeiro, SBG. v. 2 p. 740-753.

CAROZZI, A.V; FALKENHEIN, F.U.H; CARNEIRO, R.G; ESTEVES, F.R.; CONTREIRAS, C.J.A. 1975. Análise Ambiental e Evolução Tectônica Sinsedimentar da Seção Siluro-Carbonífera da Bacia do Maranhão. Rio de Janeiro, PETROBRÁS/CENPES. v. 1, 49 p. (Série Ciência-Técnica-Petróleo 7).

CHANG, K.H. 1975. Unconformity-bounded stratigraphic units. Geol Soc. Amer. Bull, 86:1544-1552.

FARINA, M. 1974. Seqüência plumbífera do Araripe-mineralização sulfetada no cretáceo sedimentar brasileiro. In: CONOR. BRAS. GEOL., 28. Porto Alegre, 1974. Anais... Porto Alegre, SBG. v. 6, p. 61-77.

FEITOSA, M.C. 1987. Fades Sedimentares e Modelo Deposidonal dos Arenitos Inferiores do Vale do Cariri. Recife. 73 p. (Dissertação de Mestrado, UFPE)

FISHER, W.L. \& BROWN L.F., Jr. 1972. Clastic Depositional Systems: a Genetic Approach to Fades Analysis. Austin, Univ. Texas/Bur. Econ. Geol. 211 p.
GASPARY, J. \& ANJOS, N.F.R. 1964. Estudo Hidrogeológico de Juazeiro do Norte - Ceará. Recife, SUDENE. 25 p. (Série Hidrogeologia 3).

GHIGNONE, J.I. 1972. Ensaio de paleogeografia do Nordeste e as seqüências sedimentares. In: CONOR. BRAS. GEOL., 26. Belém, 1972. Anais... Belém, SBG. v. 3, p. 21-28.

GHIGNONE, J.1.1979. Geologia dos sedimentos fanerozóicos do Estado da Bahia. In: INDA, H.A. ed. Geologia e Recursos Minerais do Estado da Bahia. Salvador, SME/BA. p. 24-117. (Textos Básicos 1).

GHIGNONE, J.I.; COUTO, E.A.; ASSINE, M.L. 1986.Estratigrafiae estrutura das Bacias do Araripe, IguatueRiodoPeixe. In: CONOR. BRAS. GEOL., 34. Goiânia, 1986. Anais... Goiânia, SBG. v.1, p. 271-285.

HAMBREY, M.J. \& HARLAND, W.B. (eds.) 1981. Earth's Pre-Pleistocene Glacial Record. Cambridge, Cambridge Univ. Press. 1004 p.

HASHIMOTO, A.T.; APPI, C.J.; SOLDAN, A.L.; CERQUEIRA, J.R. 1987. O neo-Alagoas nas Bacias do Ceará, Araripe e Potiguar (Brasil): caracterização estratigráfica e paleoambiental.tov. Brás. Geoc., 17(2): 118-122.

LEONARDI, G. \& BORGOMANERO, G. 1981. Sobre uma possível ocorrência de Omithischia na Formação Santana, Chapada do Araripe (Ceará). Rev. Bras. Geoc., 11:1-4.

LIMA, M.R. 1978a. Palinologia da Formação Santana (Cretáceo do Nordeste do Brasil). São Paulo. 335 p. (Tese de Doutoramento, IG/USP).

LIMA, M.R. 1978b. Microfósseis da Formação Exu - Cretáceo do Nordeste do Brasil. In: CONOR. BRAS. GEOL., 30. Recife, 1978. Anais... Recife, SBG. v. 2, p. 965-969.

LIMA, M.R. 1978c. O paleoambiente deposicional da Formação Santana (Grupo Araripe) segundo evidências palinológicas. In: CONOR BRAS. GEOL., 30. Recife, 1978. Anais... Recife, SBG. v. 2, p. 970-974.

LIMA, M.R. 1979. Considerações sobre a subdivisão estratigráfica da Formação Santana - Cretáceo do Nordeste do Brasil. Rev. Bras. Geoc. 9(2):116-121

LIMA, M.R. \& PERINOTTO, J. A. J. 1984. Palinologia de sedimentos da parte superior da Formação Missão Velha, Bacia do Araripe. Geociências (UNESP), 3:67-76

MABESOONE, J.M. \& TINOCO, LM. 1973. Paleoecology of Aptian Santana Formation (Northeastern Brazil). Palaeogeogr., Palaeoclim. Paleaeocol, 14(2):87-118.

MARTILL, D.M. 1988. Preservation offish in the Cretaceous Santana Formation of Brazil. Paleontology, 31:1-18.

MARTINS-NETO, R.G. 1990. Sistemática dos Ensifera (Insecta, Orthopteroida) da Formação Santana Cretáceo Inferior do Nordeste do Brasil. São Paulo. 267 p. (Dissertação de Mestrado, IG/USP).

MORAES, J.F.S.; SANTOS, J.S.; MASCARENHAS, J.C. 1976. Projeto Santana. Etapa I. Recife, DNPM/CPRM. v. 1, 269 p. (Relatório Final).

PONTE, F. C. \& APPI, C.J. 1990. Proposta de revisão da coluna litoestratigráfica da Bacia do Araripe. In: CONOR. BRAS. GEOL., 36. Natal, 1990. Anais... Natal, SBG. v. 1. p. 211-226.

PRICE, L.1.1971. A presença de Pterosauria no Cretáceo Inferior da Chapada do Araripe, Brasil. An. Acad. bras. Ciênc., 43(supl.):s451-461.

PRICE, L.1.1973. Quelônio Amphychelidia no Cretáceo Inferior do Nordeste do Brasil. Rev. Bras. Geoc., 3(2):84-95.

RAND, H.M. \& MANSO, V.A.V. 1984. Levantamento gravimétrico e magnetométrico da Bacia do Araripe. In: CONOR. BRAS. GEOL., 33. Rio de Janeiro, 1984. Anais... Rio de Janeiro, SBG. v. 4, p. 2011-2016.

REGALI, M.S.P. 1989. A idade dos evaporitos da plataforma continental do Ceará, Brasil, e sua relação com os outros evaporitos das bacias nordestinas. Boi. 1G-USP, p. 139-143. (Publ. Esp. 7). 
SANTOS, MEM. 1981 Ambiente dqxwicional da FonnaçSo Santana, Chapada do Anripe (PE/PI/CE). In: CONOR. BRAS. GEOL.. 32. Salvador, 1982. Anais... Salvador. SBG. v. 4, p. 1412-1426.

SILVA, M.A.M. 1983. The Araripe Basin, Northeastern Brazil: Regional Geology and Fades Analysis of a Lower Cretaceous Evaporitic Depositional Complex. EUA. 290 p. (Tese de Doutoramento, Columbia University).

SILVA, M.A.M. 1986a. Lower Cretaceous unconformity truncating evaporitecarbonate sequence, Araripe Basin, Northeastern Brazil. Rev. Bras. Geoc., 16(3):306-310.

SILVA, M.A.M. 1986b. Lower Cretaceous sedimentary sequences in the Araripe Basin, Northeastern Brazil: a revision. Rev. Bras Geoc., 16(3):311-319

SILVA, M.A.M. 1988. Evaporitos do Cretáceo da Bacia do Araripe: ambientes de deposição e história diagenétíca. Bo/. Geoc. PETROBRAS, 2(1):53-63.

SILVA SANTOS, R. \& VALENÇA, J.G. 1968. A Formação Santana e sua paleoictiofauna. An. Acad. bras. Ciênc., 40(3):339-360.

SMALL, HI., 1913. Geologia e Suprimento de Água Subterrânea no Piauhy e Parte do Ceará. Recife, Insp. Obras Contra Secas. 80 p. (Publicação 25).
VIANA, CF.; GAMA, E.G., Jr.; SIMÕES, A.; MOURA, JÁ;; FONSECA, J.R.; ALVES, RJ. 1971. Revisão estratígráfica da Bacia Recôncavo/ Tucano. Boi Técn. PETROBRÁS, 146(3/4):157-192.

VIANA, M.S.S.; BRITO, P.M.;TELLES JR., A.C.I 989. Paleontologia de uma camada de folhelhos pirobetuminosos do Membro Romualdo, Formação Santana, na mina Pedra Branca, Município Nova Olinda, Ceará. In: CONGR. BRÁS. PALEONT., 11. Curitiba, 19S9. Anais... Curitiba, SBP. V. 1 , p. $207-217$

WARREN. J.K. 1982. The hidrological setting, occurrence and significance of gypsum in late Quaternary salt lakes in South Australia. Sedimentology,

WARREN, J.K. \& KENDALL, C.S.S. 1985. Comparison of sequences formed in marine sabkha (subaerial) and salina (subaqueous) setting-modem and ancient. AAPG Bull, 69(6):1013-1026.
MANUSCRITO A728

Recebida em 4 de julho de 1992

Revisão do autor em 19 de agosto 1992

Revisão aceita em 20 de agosto 1992 